\title{
Sugary beverage consumption mediates the relationship between late chronotype, sleep duration, and weight increase among undergraduates: a cross-sectional study
}

Wei $\mathrm{Li}^{1,2+}$, Mengyun $\mathrm{Wu}^{3 \dagger}$, Fang Yuan ${ }^{1,2}$ and Huadong Zhang ${ }^{1,2^{*}}$

\begin{abstract}
Background: The study aimed to explore whether sugary beverage consumption is a key mediator of late chronotype, sleep duration, and weight increase in college students in China.

Methods: The cross-sectional study was conducted in four universities using a sample of 800 undergraduate students recruited by cluster sampling. A self-reported questionnaire was given out to collect information, including the characteristic of social demography, state of physical exercise and sugary beverage intake, the types of chronotype, and psychological conditions. Then, two structural equation models (SEMs) were constructed to test the mediating effect of sugary beverage consumption.

Results: The significant indirect effect of sugary beverage consumption was found between chronotype and BMI (effect $=-0.03, \mathrm{SE}=0.01,95 \% \mathrm{Cl}[-0.05,-0.02]$ ) and between sleep duration and BMI (effect $=-0.12, \mathrm{SE}=0.05$, $95 \% \mathrm{Cl}[-0.16,-0.09])$. In addition, physical exercise and psychological condition also play mediating effects between chronotype and BMI (effect $=-0.04, \mathrm{SE}=0.01,95 \% \mathrm{Cl}[-0.06,-0.01]$ and effect $=-0.03, \mathrm{SE}=0.02$, $95 \% \mathrm{Cl}[-0.05,-0.01])$, but their mediating effect was not found between sleep duration and BMI.

Conclusion: Preventive measures should be taken to decrease student's sugary beverage consumption, improve physical exercise, and increase individual well-being to avoid the harmful effects of eveningness. Moreover, the issue of short sleep duration among college students may be further investigated in future research.
\end{abstract}

Keywords: Sleep duration, Chronotype, BMI, Sugary beverage , College student

\section{Introduction}

Obesity has significantly become a severe public health problem, which has risen as a common social and medical phenomenon and is associated with the growth of the risk for chronic diseases, such as cancers, hypertension, type 2 diabetes, and cardiovascular disease [1-3]. Along with China's increasing productivity level and people's rapid consumption level over the past years, this issue has slowly attracted attention on overnutrition among the Chinese population $[4,5]$. A cross-sectional

\footnotetext{
* Correspondence: cdczhanghuadong@163.com

†Wei Li and Mengyun Wu contributed equally to this work.

${ }^{1}$ Department of Occupational Health Surveillance, Chongqing 400016, China

${ }^{2}$ Center for Disease Control and Prevention, Chongqing 400016, China

Full list of author information is available at the end of the article
}

survey found that China has encountered a severe prevalence of overweight/obesity at $45 \%$ in 2011 compared with $25 \%$ in 1991 [6-9]. Thus, exploring the epidemiological paths of obesity is extremely urgent to further conduct relevant control and prevention work.

In recent years, the relationship between sleep and weight has been mentioned [10-12]. It includes several factors, especially for sleep duration. Moreover, inadequate sleep duration may be associated with BMI increase [13]. However, few studies examined the causal relationship between behavioral risk (high-energy intake and low physical exercise), sleep factors, and weight outcome (e.g., overweight/obesity). In addition, chronotype as a characteristic sleep index has been overlooked on obesity research, and chronotype can obviously reflect

(c) The Author(s). 2018 Open Access This article is distributed under the terms of the Creative Commons Attribution 4.0 International License (http://creativecommons.org/licenses/by/4.0/), which permits unrestricted use, distribution, and reproduction in any medium, provided you give appropriate credit to the original author(s) and the source, provide a link to the Creative Commons license, and indicate if changes were made. The Creative Commons Public Domain Dedication waiver (http://creativecommons.org/publicdomain/zero/1.0/) applies to the data made available in this article, unless otherwise stated. 
individual sleep and physical statuses on the time dimension [14-17]. To illustrate, a cross-sectional survey of a large sample by Roeeneberg and team members found an inverse relationship between late chronotype and overweight/obesity [18]. Interestingly, chronotype slowly changed during adolescence and even early adulthood [19]. For example, departing from parental supervision and lacking a reasonable schedule, college students are inclined to late chronotype [20]. Moreover, individual's socialization has also been reported as follows: college students preferred to seek social support, thereby triggering their willingness to join inter-recreational activities, which may lead to the development of a late chronotype [21]. Several college students also experience deleterious health behaviors, thereby rendering them vulnerable to weight gain and even overweight/ obesity. Overweight/obese people would suffer from mental disorders, such as depression [22]. Baron and colleagues found that $12 \%$ of college students reported experiencing chronic depressive symptoms following sleep disturbance [23]. With respect to the relationship between eating patterns and chronotype, the individuals categorized as evening types consume a large amount of high-energy food and beverages than morning types and neutral types $[24,25]$. This phenomenon might be because late chronotype prolongs individual drop asleep time, and these people feel more tired and hungry than the other types. Lack of sleep was correlated with a high-sugary beverage consumption and low physical exercise time [26, 27]. Notably, the issue of sugary beverage consumption pattern in China raises widespread concerns, although sugary beverages have been harmful associations with a higher incidence of type 2 diabetes, obesity, and cardiovascular $[28,29]$. However, they are still popular in China such as Coca-Cola and PepsiCo carbonated drinks, and their sales drastically increased 149 and 129\% in China, respectively [30]. Moreover, Geo et al. used the information from Chinese Nutrition and Health Surveillance: 2010-2012 (CHNS:2010-2012) to investigate the consumption of sugar-sweetened beverages among 18 years old and above. The longitudinal investigation involved 45,203 respondents and 150 sites of 31 provinces, which found Chinese adults consuming sugary beverages were $49.2 \%$ (men) and $50.8 \%$ (women), and carbonated beverages accounted for the highest proportion in beverages consumption (39.8\%). The founding suggested that the government should develop nutritional education to reduce the consumption of sugary beverage [31]. University stage is a critical period for students to culture correct values and behavior habits. Because college students were first to leave the parents and obtain more responsible for arranging own schedule, some potential problems may emerge such as stimulation intake, and sugary beverages would become readily available products used widely. The abovementioned risk factors could provide a transitive path between sleep status and BMI. Overall, college students stand as the ideal population to explore the association between chronotype and BMI.

Descriptive studies on the association between sleep and BMI demonstrated that their correlation was identified by conducting univariate analysis and multiple linear regression. However, the findings were limited to direct effect of the factors and did not take interaction into consideration. Furthermore, sugary beverages' use has the characteristics of behavior-related sleep and closely relates BMI, but the indirect effect role of sugary beverages on relationships between BMI, chronotype, and other behavior-related factors is still unclear. The structural equation modeling (SEM) analysis is the method considering the indirect effect of the variables, but few studies employed it in examining the effects of mediation on BMI. Therefore, to fill the above gaps in the current studies, we conducted two multiple mediation models to investigate the inter-effect relationship among chronotype, sleep duration, and BMI values, with sugary beverage and physical exercise time as mediators. The hypotheses were as follows: (1) chronotype, sugary beverage consumption, physical exercise status, and sleep duration have a direct effect on BMI; (2) sugary beverage consumption and physical exercise play a mediating role among chronotype, sleep duration, and BMI. This study will help support evidence to enhance prevention and intervention measures in promoting individual weight regulation among the college student population.

\section{Materials and methods Study design and sample}

A total of 800 college students aged $19.8 \pm 1.1$ were recruited to participate in this study from four universities from April to July 2018 in Shapingba District, namely, Chongqing University, Chongqing Normal University, Southwest Politics and Law University, and Chongqing Foreign Language University. Twelve classes were randomly drawn out from the above universities (three classes for each university and ranging from freshmen to juniors). Then, all selected students were invited to complete this project. Self-reported questionnaires were distributed with students by their respective class monitors or teachers, and participants filled out the questionnaires for each question on the spot. Any problem during the investigation was explained by trained investigators, and informed consent was provided before questionnaire distribution. Information data were recorded by two investigators. Finally, we collected 788 completed questionnaires, with a response rate of $98.5 \%$. Twelve questionnaires, which had many incomplete answers, were excluded. We included 788 respondent information in the last data processing and analysis. 


\section{Primary measures}

\section{Demographic variable evaluation}

All respondents' socio-demographic information was collected by certain subjective items, including years, grade (grade $1 /$ grade $2 /$ grade 3 ), gender (female/male), height $(\mathrm{cm})$ and weight $(\mathrm{kg})$, residence (dormitory/apartment/home), types of university (Chongqing University/ Chongqing, Normal University/Southwest Politics, and Law University/Chongqing Foreign Language University). BMI was calculated by weight $(\mathrm{kg}) /$ height $\left(\mathrm{cm}^{2}\right)$ as continuous variable to fit mediation model. Furthermore, BMI was divided into four categories to present more basic information in descriptive analysis, namely, underweight $\left(\mathrm{BMI}<18.5 \mathrm{~kg} / \mathrm{m}^{2}\right)$, normal weight $(18.5$ $\left.\mathrm{kg} / \mathrm{m}^{2} \leq \mathrm{BMI}<24 \mathrm{~kg} / \mathrm{m}^{2}\right)$, overweight $\left(24 \mathrm{~kg} / \mathrm{m}^{2} \leq \mathrm{BMI}\right.$ $\left.<28 \mathrm{~kg} / \mathrm{m}^{2}\right)$, and obese $\left(\mathrm{BMI} \geq 28 \mathrm{~kg} / \mathrm{m}^{2}\right)$.

\section{Sleep duration and chronotype measures}

Individual sleep pattern may show a significant difference between working days and rest days. Moreover, students could experience an inadequate sleep duration, even developing "sleep debt" during working days, and they would correct lost duration by prolonging the wake-up time during their free days. Therefore, mean sleep duration was measured as [(work day sleep duration time $\times 5)+($ rest day sleep duration time $\times 2)] / 7$ over past week. We asked the participants to report their sleep onset time and sleep offset time; the night sleep duration values are calculated as (sleep offset timesleep onset time). The individual chronotype was obtained using the Morningness-Eveningness Questionnaire (MEQ) [32], which comprised 19 questions associated with respondent's individual sleep pattern according to their feeling during the latest several weeks, such as morningness, intermediate, and eveningness, as a valid tool determining the circadian typology in groups and reflecting the appropriate scale property in the Chinese population [33]. The MEQ score distributions range from 16 to 86 . The higher total scores mean that the persons are classified as morning types, and the lower total scores show strong evening types. The morningness scores range from 59 to 86 , the intermediate scores range from 42 to 58 , and the eveningness scores range from 16 to 41 . Cronbach's $\alpha$ was 0.94 in this study.

\section{Sugary beverage consumption and physical exercise time calculation}

Sugary beverage consumption was assessed using the subjective problems: "How many bottles or tins of sugary beverage do you usually drinks on average per day over past week? (work days and rest days, respectively)" mean sugary beverage consumption was measured as [(work day consumption $\times 5)+($ rest day consumption $\times 2)] / 7$. Sugary beverages were defined as carbonated beverages, soft beverages, sweetened juices, and others. Then, reference standards were provided to participants that one bottle approximately equal to $500 \mathrm{ml}$ and one tin approximately equal to $330 \mathrm{ml}$. Moreover, physical exercise time was also collected by an open question: "How much time for the past week do you usually spend on moderate exercise, such as carrying packet on average per day over past week (minutes/hours)? (work days and rest days, respectively)" mean physical exercise time was measured as [(work day physical exercise time $\times 5)+($ rest day physical exercise time $\times 2)] / 7$. Moderate exercises include fast walking, dancing, doing homework, carrying medium weight goods, and so on.

\section{Mental condition determination}

The Depression Anxiety Stress Scale 21 (DASS-21) is a self-reported instrument with three subscales to diagnose individual psychological distress over past week, including anxiety, depression, and stress dimension [34]. Three subscales were classified into three levels, namely, low, moderate, and severe. Low scores were cut off as depression $(\leq 13)$, anxiety $(\leq 9)$, and stress $(\leq 14)$; middle scores were cutoff as depression (14-20), anxiety (10-14), and stress (14-25); severe scores were cut off as depression $(\geq 21)$, anxiety $(\geq 15)$, and stress $(\geq 26)$. The DASS-21 has been extensively applied for the Chinese students' mental state study [35]. Cronbach's $\alpha$ were $0.78,0.82$, and 0.84 in this study.

\section{Statistical analysis}

SPSS version 22 was conducted for this statistical analyses (SPSS Inc., Chicago, IL, USA), and structural equation models were performed with SPSS PROCESS. Survey data were logged in Excel and checked by two people. Missing data were disposed using multiple imputations by the SPSS, and gender, grade, residence, and type of university were regarded as auxiliary variables to impute missing data, and the added times were 20. The descriptive analyses were employed to summarize the basic characteristics of data, which were shown as mean \pm standard deviation (mean \pm SD) or numbers and proportions $(N, \%)$. In addition, Pearson correlation analysis was operated to explore the possible relationship among independent variables, mediator, control variables, and dependent variables. Then, two mediation models were constructed to identify the direct/indirect effect of sugary beverage consumption. (1) The first model was set up among sleep duration, sugary beverage consumption, and BMI. (2) The second model was established among chronotype, sugary beverage consumption, and BMI. (3) To avoid exaggerating the influence of sugary beverage consumption, physical exercise time and metal state were brought into the two multiple mediation models. (4) To realize that the general data were no different 
among individuals in baselines, three control variables (gender, years, grade, residence) were selected in SEM. In this study, bootstrapping technique was used to estimate 10,000 resamples to reduce type I error [36, 37]. Indirect and direct effects were represented by bias-corrected 95\% confidence intervals (95\% CIs). The significant differences among all analyses were regarded as $p<0.05$ and adopted the two-sided test.

\section{Results}

\section{Characteristic of sample}

All the charateristic are showed in Table 1 . This study involved 800 undergraduate students. A total of 788 participants aged $19.8 \pm 1.1$, which include 271 (34.4) males and 517 (65.6\%) females, completed all the questions. A total of 722 (91.6\%) lived on campus, 26 (3.3\%) lived in apartments, and 40 (5.1\%) lived at home. A total of 212 (26.9\%) were grade 1 students, 255 (32.4\%) were grade 2 students, and 321 (40.7\%) were grade 3 students. A total of 199 (25.3\%) were from Chongqing University, 207 (26.3\%) were from Chongqing Normal University, 174 (22.1\%) were from Southwest Politics and Law University, and 208 (26.4\%) were from Chongqing Foreign Language University. A total of 158 (20.1\%) were underweight, 585 (74.2\%) were normal weight, 32 (4.1\%) were overweight, and 13 (1.6\%) were obese. The average sleep duration was $7.6 \pm 1.1 \mathrm{~h}$, and the average physical exercise time was $4.6 \pm 2.9 \mathrm{~h}$. The average sugary beverage consumption was $0.7 \pm 0.5 \mathrm{l}$. With regard to chronotype and mental state, a total of $172(21.8 \%)$ were morningness, 495 (62.8) were intermediate, and 121 (15.4\%) were eveningness. A total of $81(10.2 \%)$ were middle/high depression, 521 (66.0\%) were middle/high stress, and 161 (20.5\%) were middle/high anxiety.

\section{Pearson correlation of main variables}

The Pearson correlation analysis was conducted between continuous variables shown in Table 2. The significant positive correlation was found between age and BMI, age and sleep duration, BMI and sugary beverage intake, BMI and sleep duration, BMI and chronotype, sugary beverage consumption and DASS-21 scores, physical exercise time and chronotype, and BMI and DASS-21 scores. The significant negative correlation was found between BMI and physical exercise time, DASS-21 scores and chronotype, sugary beverage intake and sleep duration, and sugary beverage intake and chronotype.

\section{Mediating role of sugary beverage use in the relationship between chronotype and BMI}

Figure 1 and Table 3 present the indirect and direct effects of the first mediation model. With regard to the effects of chronotype, the positive direct effects were found between chronotype and physical exercise time
$(B=0.39, \mathrm{SE}=0.03, p<0.01)$, and negative direct effects were found between chronotype and DASS-21 score $(B=-0.12, \mathrm{SE}=0.04, p<0.01)$, chronotype and sugary beverage consumption $(B=-0.15, \mathrm{SE}=0.03, p<0.01)$, and chronotype and $\mathrm{BMI}(B=-0.42, \mathrm{SE}=0.04, p<0.01)$. Therefore, a low chronotype score may generate an increased sugary beverage consumption, less physical exercise, and severe mental condition, even obesity.

The indirect effects of mediators were further checked, including sugary beverage intake, physical exercise time, and DASS-21 score. Significant indirect effects were found in the first mediation model, respectively, sugary beverage consumption (effect $=-0.03, \mathrm{SE}=0.01,95 \% \mathrm{CI}$ $[-0.05,-0.02])$, physical exercise time (effect $=-0.04$, $\mathrm{SE}=0.01,95 \%$ CI $[-0.06,-0.01])$, and DASS-21 score (effect $=-0.03, \mathrm{SE}=0.02,95 \% \mathrm{CI}[-0.05,-0.01])$. Moreover, the indirect effect of sugary beverage consumption and DASS-21 on BMI has a significant positive association $(B=0.20, \mathrm{SE}=0.02, p<0.01$ vs. $B=0.22$, $\mathrm{SE}=0.04$, $p<0.01)$, thereby indicating that sugary beverage intake may be an undesirable factor between late chronotype and high BMI. In addition, the indirect effect of physical exercise time on BMI shows a significant negative association $(B=-0.09, \mathrm{SE}=0.03, p<0.05)$. Thus, physical exercise time can be considered a protective factor between late chronotype and high weight. The total effect model has contributed approximately $26 \%$ of the variables in BMI $\left(R^{2}=0.26, p<0.01\right)$. Table 4 reports the indirect mediation of sugary beverage use in the model.

\section{Mediating role of sugary beverage use in the relationship between sleep duration and BMI}

Figure 2 and Table 5 present the indirect and direct effects of the first mediation model. Concerning the effects of sleep duration, the positive direct effects were found between sleep duration and sugary beverage intake $(B=-0.54, \mathrm{SE}=$ $0.03, p<0.01)$, sleep duration, and $\mathrm{BMI}(B=-0.13, \mathrm{SE}=$ $0.03, p<0.01)$. Thus, these results may point out that insufficient sleep duration would aggravate the risk of overweight/ obesity and additional sugary beverage intake. However, the significant association was not found between sleep duration and physical exercise time and between sleep duration and the DASS-21 scores.

The indirect effect of mediators was explored by bootstrapping resampling. Interestingly, the significant indirect effects of sugary beverage intake were also found in the model (effect $=-0.12, \mathrm{SE}=0.05,95 \%$ CI $[-0.16,-0.09]$ ), and the direct effect of sugary beverage intake on BMI was positive $(B=0.23, \mathrm{SE}=0.03, p<0.05)$. Therefore, sugary beverage consumption may also be a risk factor on the association between sleep duration and BMI. The total effect model has contributed approximately $21 \%$ of the variables in BMI $\left(R^{2}=0.21, p<0.01\right)$. Table 6 reports the indirect mediation of sugary beverage use in the model. 
Table 1 Demographic characteristics of undergraduate students in Chongqing, China, 2018 ( $n=788$, response rate: 98.5\%)

\begin{tabular}{|c|c|c|}
\hline Variable & Number & Percentage (mean $\pm \mathrm{SD}$ ) \\
\hline Age & 788 & $19.8 \pm 1.1$ \\
\hline \multicolumn{3}{|l|}{ Grade } \\
\hline Grade 1 & 212 & $26.9 \%$ \\
\hline Grade 2 & 255 & $32.4 \%$ \\
\hline Grade 3 & 321 & $40.7 \%$ \\
\hline \multicolumn{3}{|l|}{ Gender } \\
\hline Male & 271 & $34.4 \%$ \\
\hline Female & 517 & $65.6 \%$ \\
\hline \multicolumn{3}{|l|}{ Residence } \\
\hline School & 722 & $91.6 \%$ \\
\hline Apartments & 26 & $3.3 \%$ \\
\hline Home & 40 & $5.1 \%$ \\
\hline \multicolumn{3}{|l|}{ Type of university } \\
\hline Chongqing University & 199 & $25.3 \%$ \\
\hline Chongqing Normal University & 207 & $26.3 \%$ \\
\hline Southwest Politics and Law University & 174 & $22.1 \%$ \\
\hline Chongqing Foreign Language University & 208 & $26.4 \%$ \\
\hline \multicolumn{3}{|l|}{ BMI value } \\
\hline $\mathrm{BMI}<18.5$ (underweight) & 158 & $20.1 \%$ \\
\hline $18.5 \leq \mathrm{BMI}<24$ (normal weight) & 585 & $74.2 \%$ \\
\hline $24 \leq \mathrm{BMl}<28$ (overweight) & 32 & $4.1 \%$ \\
\hline BMI $\geq 28$ (obesity) & 13 & $1.6 \%$ \\
\hline Sleep duration (hours) & 788 & $7.6 \pm 1.1$ \\
\hline \multicolumn{3}{|l|}{ Chronotype } \\
\hline Morningness & 172 & $21.8 \%$ \\
\hline Intermediate & 495 & $62.8 \%$ \\
\hline Eveningness & 121 & $15.4 \%$ \\
\hline Sugary beverage intake daily ( $L /$ day) & 788 & $0.7 \pm 0.5$ \\
\hline Physical exercise time (hours) & 788 & $4.6 \pm 2.9$ \\
\hline \multicolumn{3}{|l|}{ DASS-21 } \\
\hline \multicolumn{3}{|l|}{ Depression } \\
\hline Low & 707 & $89.7 \%$ \\
\hline Middle & 77 & $9.7 \%$ \\
\hline High & 4 & $0.5 \%$ \\
\hline \multicolumn{3}{|l|}{ Stress } \\
\hline Low & 267 & $33.8 \%$ \\
\hline Middle & 514 & $65.2 \%$ \\
\hline High & 7 & $0.8 \%$ \\
\hline \multicolumn{3}{|l|}{ Anxiety } \\
\hline Low & 627 & $79.6 \%$ \\
\hline Middle & 151 & $19.2 \%$ \\
\hline High & 10 & $1.3 \%$ \\
\hline
\end{tabular}


Table 2 Correlation of main variables

\begin{tabular}{|c|c|c|c|c|c|c|c|}
\hline & 1 & 2 & 3 & 4 & 5 & 6 & 7 \\
\hline 1. Age & 1 & & & & & & \\
\hline 2. BMI & $0.07^{*}$ & 1 & & & & & \\
\hline 3. Sugary beverage intake & -0.04 & $0.29 * *$ & 1 & & & & \\
\hline 4. Physical exercise time & -0.05 & $-0.12^{* *}$ & 0.06 & 1 & & & \\
\hline 5. Sleep duration & $0.10^{* *}$ & $0.19 * *$ & $-0.12 * *$ & -0.04 & 1 & & \\
\hline 6. DASS-21 & $-0.08^{*}$ & $0.28^{* *}$ & $0.54 * *$ & 0.02 & -0.05 & 1 & \\
\hline 7. Chronotype & -0.04 & $0.51 * *$ & $-0.15^{* *}$ & $0.39^{* *}$ & $-0.11^{* *}$ & $-0.12^{* *}$ & 1 \\
\hline
\end{tabular}

Note. ${ }^{*} p<0.05 ;{ }^{* *} p<0.01$

\section{Discussion}

Chronotype and sleep duration are often associated with human weight regulation [18, 20, 38]. In addition, daily behavior habits that may not be neglected are attached to the individual sleep pattern, such as sugary beverage intake and physical exercise. In this study, we attempted to explore that sugary beverage intake significantly mediates cross-sectional associations between sleep duration, chronotype, and BMI; moreover, the significant indirect effect of sugary beverage intake existed in the two models. These novel results may enrich the relationship of the paths between sleep and weight, suggesting that good sleep habits may promote a fit weight and that this process may be developed through low-sugary beverage intake.

In this study, the mediating role of sugary beverage intake was illustrated in the two models, and these results were supported by previous studies [39, 40]. Late chronotype and short sleep duration may be associated with high-sugary beverage intake among adolescents and students. To illustrate, Sampasa-Kanyinga and colleagues conducted a cross-sectional study, including 9473 adolescents aged 11-20 years old, which reported that short sleep duration was associated with 1.64 odds of sugary beverage consumption in middle school students [39]. Moreover, Kanerva and colleagues examined 4493 college subjects' socio-demographic backgrounds, sleep patterns, and dietary intake habits. Using these data, they found that subjects in the lowest chronotype scores consumed more soft beverages than the highest group [40]. The results of our study extend previous findings and add to our views and opinions by suggesting that chronotype and sleep duration were associated with BMI, and this relationship was mediated by sugary beverage intake.

The potential mechanism on sleep pattern and sugary beverage consumption was not thoroughly explained, probably for several reasons. First, the individual with a late chronotype or short sleep duration may experience an irregular eating habit and a perceived hunger, even overeating [41]. A meta-analysis by Cappuccio demonstrated that the pooled odds ratio for short sleep duration and obesity was 1.89 in children and 1.55 in adults [42]. These outcomes may intensely relate to hormonal secretion in the body. Inefficient sleep may influence hormone levels, such as satiety hormones, leptin, and ghrelin [43, 44]. Epidemiological studies have also demonstrated that late chronotype or short sleep duration was associated with significantly high insulin and low leptin levels in the college population [20, 45]. Second, late chronotype and short sleep duration would generate sleep debt, but students would go to school in the morning the next day, and the risk of excessive daytime sleepiness would increase; then, sugary beverage consumption would play a stimulant role in improving individual attention $[39,46]$. Third, late chronotype and short sleep duration could develop into sleep disorders in severe condition, and this condition means that an individual's immune function will decrease and levels of inflammation increase. Inflammation regulates energy metabolism in both physical and mental conditions. An individual's chronic inflammatory response, when not effectively controlled, leads to energy metabolism disorders and insulin resistance [47]. Hence, patients' outcome would deteriorate if they consume sugary beverages.

Physical exercise as significant to maintaining the stabilization of the human body is common knowledge, including physical and psychological health [48]. The association between sedentary behavior and other physical inactivity and cardiovascular disease, type 2 diabetes, and obesity have attracted significant attention in the field of public health [49]. In our study, the significant indirect effect of physical exercise time was found between chronotype and BMI. A systematic review generated similar results, which found that morningness could have a merit in perceived exertion, less fatigue, and better performance in submaximal physical exercise and athletic tasks [50]. One reasonable explanation is that the individual physical exercise state is influenced by exogenous and endogenous factors, such as exercising at day or night time and when to awake, and eveningness seemingly requires an extra time for physical 


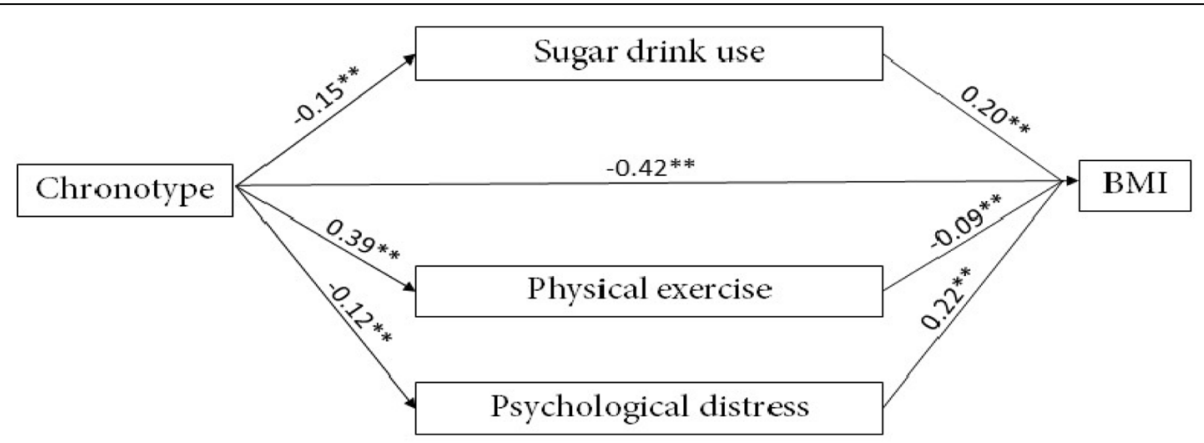

Fig. 1 (Wei Li and Mengyun Wu). Mediating role of sugary beverage use in the relationship between chronotype and BMI. Note. ${ }^{* *} p<0.01$

preparations after getting up. However, the indirect effect was not found between sleep duration and BMI. This reason may be attributed to the differences in measurement methods: the sleep duration was calculated by individual average sleep time, which has definite limitations. If one person has a sleep onset at 21:00 and sleep offset 9:00, he/she has slept for $12 \mathrm{~h}$, but if he/she goes to bed at 24:00 and gets up at 12:00, he/she has also slept for $12 \mathrm{~h}$. In other words, average sleep duration only counts for your total sleep time rather than when you go to sleep. By contrast, chronotype was calculated not only by inquiring on sleep time but also by asking one's sleep habit and physical condition. Hence, late chronotype refers to individuals who go to bed late and get up late; thus, they may lose considerable time for exercise and activities. Moreover, daytime napping would happen frequently in eveningness, leading the person to feel tired and less inclined to go outside.

Finally, subjects' psychological conditions were evaluated in the two models. The significant indirect effects were found in the first model but not in the second

Table 3 Direct mediating of role sugary beverage use in the relationship between chronotype and BMI

\begin{tabular}{|c|c|c|c|c|}
\hline Paths & $B$ & SE & $95 \% \mathrm{Cl}$ & $p$ \\
\hline \multicolumn{5}{|l|}{ Chronotype } \\
\hline BMI & -0.42 & 0.04 & $(-0.48,-0.34)$ & $<0.01$ \\
\hline Sugar drink use & -0.15 & 0.03 & $(-0.21,-0.10)$ & $<0.01$ \\
\hline Physical exercise & 0.39 & 0.03 & $(0.33,0.45)$ & $<0.01$ \\
\hline Psychological distress & -0.12 & 0.04 & $(-0.20,-0.05)$ & $<0.01$ \\
\hline \multicolumn{5}{|l|}{ Sugar drink use } \\
\hline BMl & 0.20 & 0.02 & $(0.16,0.25)$ & $<0.01$ \\
\hline \multicolumn{5}{|l|}{ Physical exercise } \\
\hline BMI & -0.09 & 0.03 & $(-0.15,-0.03)$ & $<0.01$ \\
\hline \multicolumn{5}{|l|}{ Psychological distress } \\
\hline BMl & 0.22 & 0.04 & $(0.15,0.29)$ & $<0.01$ \\
\hline
\end{tabular}

model. Previous studies showed that late chronotype could also impair individual sleep quality and increase dietary intake owing to psychological factors, such as depression and stress [51, 52]. Rique and colleagues found that eveningness was associated with poor quality of sleep among medical students, which may be explained by the medical college students' extra academic pressure and thus compelled them to shorten sleep time [51]. Another study (Romo-Nava et al.) also found that eveningness increased the susceptibility for depression than morningness and intermediate; moreover, late chronotype and depression were both associated with severe perceived academic stress [52]. This conclusion further indicated the diverse effect of excessive study burden for student's sleep habits. Interestingly, we found no mediation effect of mental condition in the second model. Previous research has elaborated the association between sleep duration and depression, and their relationship may be found using the U-shape graph [53], suggesting that the individual who experienced increased or decreased sleep duration may likely lead to a depressive symptom. Two reasons explain the inconsistency of our study with the above literature. First, the mediating effect of sugary beverage intake was strong in the model and weakens the indirect effect of mental conditions. Moreover, an increased stimulant intake, such as alcohol, coffee, and carbonated beverages may aggravate depression, and the inter-effect of stimulant intake and depression requires further investigation in longitudinal studies [54]. Second, most results of participants' DASS-21

Table 4 Indirect mediating role of sugary beverage use in the relationship between chronotype and BMI

\begin{tabular}{lll}
\hline Domain & $\begin{array}{l}\text { Effect } \\
\text { (boot SE) }\end{array}$ & $\begin{array}{l}\text { Lower, upper 95\% } \\
\text { confidence interval }\end{array}$ \\
\hline Sugary beverages intake & $-0.03(0.01)$ & $(-0.05,-0.02)$ \\
Physical exercise time & $-0.04(0.01)$ & $(-0.06,-0.01)$ \\
DASS-21 scores & $-0.03(0.02)$ & $(-0.05,-0.01)$
\end{tabular}

Note. Significant mediation is highlighted in italic font 


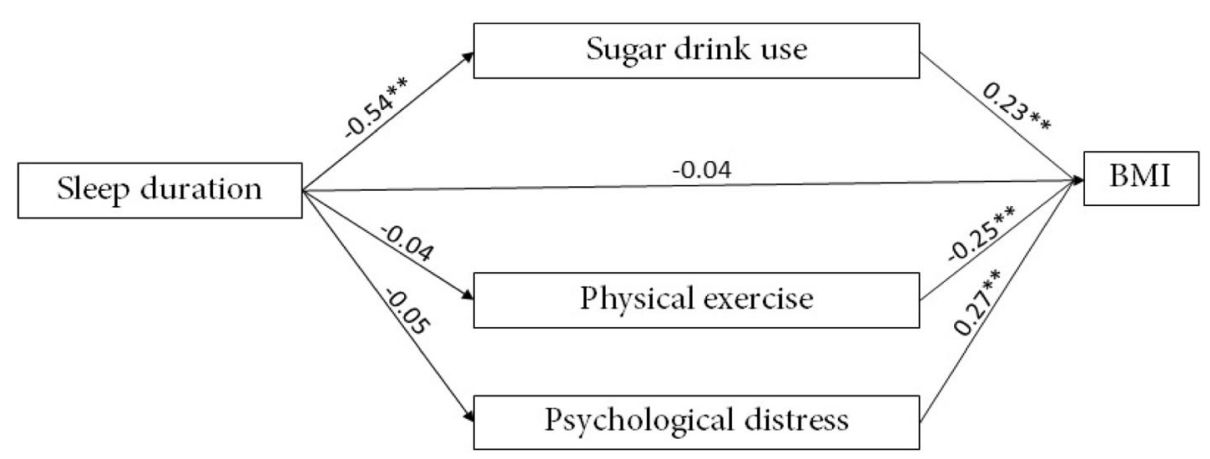

Fig. 2 (Wei Li and Mengyun Wu). Mediating role of sugary beverage use in the relationship between sleep duration and BMI. Note.* $p<0.01$

scores were mostly concentrated in the middle and low levels with a skewness distribution. Hence, a large sample survey should be conducted to achieve comprehensive psychological conditions in college students.

This study has definite limitations. First, the method design adopted a cross-sectional survey, and information and date cannot determine the results of causality. Second, the ratio of female is apparently higher than that of male in the survey population, and males and females may have significant differences in routine life. Thus, the sex bias should be focused in this study. Third, the self-reported questionnaires were used to collect information on physical exercise time and sugar drink consumption, which has the advantages of simplicity, low cost, high response rate, and convenience in processing numerical results. However, this method was hard to achieve precise quantification and lacked of some reliabilities and validities. This would be an important limitation of our study. Hence, objective measures should be adopted in

Table 5 Direct mediating role of sugary beverage use in the relationship between sleep duration and $\mathrm{BMl}$

\begin{tabular}{|c|c|c|c|c|}
\hline Paths & $B$ & SE & $95 \% \mathrm{Cl}$ & $p$ \\
\hline \multicolumn{5}{|l|}{ Sleep duration } \\
\hline BMI & -0.04 & 0.03 & $(-0.02,0.10)$ & 0.22 \\
\hline Sugar drink use & 0.54 & 0.03 & $(0.48,0.59)$ & $<0.01$ \\
\hline Physical exercise & -0.04 & 0.04 & $(-0.11,0.03)$ & 0.25 \\
\hline Psychological distress & -0.05 & 0.04 & $(-0.13,0.04)$ & 0.26 \\
\hline \multicolumn{5}{|l|}{ Sugar drink use } \\
\hline BMl & 0.23 & 0.03 & $(0.17,0.28)$ & $<0.01$ \\
\hline \multicolumn{5}{|l|}{ Physical exercise } \\
\hline BMl & -0.25 & 0.03 & $(-0.30,-0.19)$ & $<0.01$ \\
\hline \multicolumn{5}{|l|}{ Psychological distress } \\
\hline BMI & 0.27 & 0.04 & $(0.19,0.36)$ & $<0.01$ \\
\hline
\end{tabular}

future nutritional epidemiology research, such as food logs and actigraphy measured exercise parameters. Furthermore, we should pay more attention to the practical application and let the respondents know the meaning of questionnaire and minimize experimental errors. Fourth, the research was restricted to Chongqing, and individual chronotype may have an impact by living at what latitude. Thus, the result may lack richness and extensibility. Fifth, although we used the bootstrapping technique to decrease the type I error and remedy the inferiority of the sample, the large sample survey could be further carried out to cover different students with diverse majors. Finally, the kind of sugary beverages was not distinguished in this study, and diverse kinds of stimulant beverages may generate different effect sizes in the model.

\section{Conclusions}

This study found that sugary beverage intake might mediate the association among sleep duration, late chronotype, and weight gain among college students. These results could provide a possible new approach to explore the effect of food between sleep pattern and weight, which suggests that sugary beverage intake may be a risk factor to developing overweight/ obesity for eveningness. In addition, the schools should take relevant measures to decrease frequency of this exposure. For example, schools could reduce students' academic burdens after class and arrange

Table 6 Indirect mediating role of sugary beverage use in the relationship between sleep duration and BMI

\begin{tabular}{lll}
\hline Domain & $\begin{array}{l}\text { Effect } \\
\text { (boot SE) }\end{array}$ & $\begin{array}{l}\text { Lower, upper 95\% } \\
\text { confidence interval }\end{array}$ \\
\hline Sugary beverages intake & $-0.12(0.05)$ & $(-0.16,-0.09)$ \\
Physical exercise time & $0.01(0.01)$ & $(-0.01,0.03)$ \\
DASS-21 scores & $-0.01(0.01)$ & $(-0.04,0.01)$
\end{tabular}

Note. Significant mediation is highlighted in italic font 
similar chronotypes to live together. Moreover, the individual psychological conditions and physical activities have significant indirect effects between chronotype and BMI, which indicated that college students should develop a culture of effective exercise and nurture a good mind to decrease the negative effect of late chronotype on weight.

\section{Abbreviations}

BMI: Body mass index; Cl: Confidence interval; DASS-21: The Depression Anxiety Stress Scale 21; MEQ: The Morningness-Eveningness Questionnaire; SD: Standard deviation; SE: Standard error; SEM: Structural equation model; SPSS: Statistical Package for Social Science

\section{Acknowledgements}

We acknowledge the class counselors and class leaders for providing us with administrative support for this research.

\section{Funding}

This study has no funding support.

\section{Availability of data and materials}

The data will not be shared publicly because it may infringe on individual privacy, but it can be obtained from the corresponding author on reasonable request.

\section{Authors' contributions}

$W \mathrm{~L}$ and $\mathrm{HZ}$ were responsible for the conceptualization of the manuscript. MW was responsible for the methodology. WL was responsible for the validation of the manuscript. WL was responsible for the formal analysis of the study. WL and FY were responsible for the investigation of the manuscript. $\mathrm{HZ}$ was responsible for the resources of the study. FY was responsible for the data curation of the manuscript. WL was responsible for the writing and original draft preparation of the study. $\mathrm{HZ}$ was responsible for writing, reviewing, and editing the manuscript. FY was responsible for the visualization of the manuscript. $\mathrm{HZ}$ was responsible for the supervision of the study. $\mathrm{HZ}$ was responsible for the financial support of the study. All authors read and approved the final manuscript.

\section{Ethics approval and consent to participate}

The study protocol was approved by the Ethics Committee of Department of Occupational Health Surveillance, Chongqing, China (reference number 2017014). All participants submitted written informed consent.

\section{Consent for publication}

Not applicable

\section{Competing interests}

The authors declare that they have no competing interests.

\section{Publisher's Note}

Springer Nature remains neutral with regard to jurisdictional claims in published maps and institutional affiliations.

\section{Author details \\ ${ }^{1}$ Department of Occupational Health Surveillance, Chongqing 400016, China. ${ }^{2}$ Center for Disease Control and Prevention, Chongqing 400016, China. ${ }^{3}$ Chongqing Engineering research Center of Stem Cell Therapy, The Children's Hospital of Chongqing Medical University, Chongqing 400014, China.}

Received: 24 August 2018 Accepted: 29 November 2018

Published online: 22 December 2018

\section{References}

1. Flegal KM, Kruszonmoran D, Carroll MD, Fryar CD, Ogden CL. Trends in obesity among adults in the United States, 2005 to 2014. JAMA. 2016; 315(21):2284. https://doi.org/10.1001/jama.2016.6458.
2. Mozaffarian D. Dietary and policy priorities for cardiovascular disease, diabetes, and obesity: a comprehensive review. Circulation. 2016;133(2):187. https://doi.org/10.1161/CIRCULATIONAHA.115.018585.

3. Deng T, Lyon CJ, Bergin S, Caligiuri MA, Hsueh WA. Obesity, inflammation, and cancer. Annu Rev Pathol. 2016;33(12):421-49. https://doi.org/10.1007/ 978-1-4614-6819-6.

4. Popkin BM. Will China's nutrition transition overwhelm its health care system and slow economic growth? Health Aff. 2008;27(4):1064. https://doi. org/10.1377/hlthaff.27.4.1064.

5. Dearthwesley $T$, Wang $H$, Popkin BM. Under- and overnutrition dynamics in Chinese children and adults (1991-2004). Eur J Clin Nutr. 2008;62(11):1302. https://doi.org/10.1038/sj.ejcn.1602853.

6. Gordon-Larsen P, Wang H, Popkin BM. Overweight dynamics in Chinese children and adults. Obes Rev. 2013;15(S1):37-48. https://doi.org/10.1111/obr.12121.

7. Gu D, Reynolds K, Wu X, Chen J, Duan X, Reynolds RF, et al. Prevalence of the metabolic syndrome and overweight among adults in China. Lancet. 2005;365(9468):1398-405. https://doi.org/10.1016/S0140-6736(05)66375-1.

8. Wu Y, Huxley R, Li M, Ma J. The growing burden of overweight and obesity in contemporary China. Cvd Prev Control. 2009;4(1):19-26. https://doi.org/ 10.1016/j.cvdpc.2008.11.003.

9. Collaborators, M. C. O. D. Global, regional, and national age-sex specific allcause and cause-specific mortality for 240 causes of death, 1990-2013: a systematic analysis for the global burden of disease study 2013. Lancet. 2017;390(10100):1151. https://doi.org/10.1016/S0140-6736(14)61682-2.

10. Hasler G, Buysse DJ, Klaghofer R, Gamma A, Ajdacic V, Eich D, et al. The association between short sleep duration and obesity in young adults: a 13-year prospective study. Sleep. 2004;27(4):661-6. https://doi.org/10.1093/sleep/27.4.661.

11. Chen X, Beydoun MA, Wang Y. Is sleep duration associated with childhood obesity? A systematic review and meta-analysis. Obesity. 2012;16(2):265-74. https://doi.org/10.1038/oby.2007.63.

12. Gupta NK, Mueller WH, Chan W, Meininger JC. Is obesity associated with poor sleep quality in adolescents? Am J Hum Biol. 2010;14(6):762-8. https:// doi.org/10.1002/ajhb.10093.

13. Gangwisch JE, Malaspina D, Bodenalbala B, Heymsfield SB. Inadequate sleep as a risk factor for obesity: analyses of the NHANES I. Sleep. 2005;28(10): 1289-96. https://doi.org/10.1093/sleep/28.10.1289.

14. Wittmann M, Dinich J, Merrow M, Roenneberg T. Social jetlag: misalignment of biological and social time. Chronobiol Int. 2006;23(1-2):497-509. https:// doi.org/10.1080/07420520500545979.

15. Roenneberg T, Kuehnle T, Juda M, Kantermann T, Allebrandt K, Gordijn M, et al. Epidemiology of the human circadian clock. Sleep Med Rev. 2007;11(6): 429-38. https://doi.org/10.1016/j.smrv.2007.07.005

16. Roenneberg T, Keller LK, Fischer D, Matera JL, Vetter C, Winnebeck EC. Human activity and rest in situ. Methods Enzymol. 2015;552:257-83. https:// doi.org/10.1016/bs.mie.2014.11.028.

17. Roenneberg T, Wirzjustice A, Merrow M. Life between clocks: daily temporal patterns of human chronotypes. J Biol Rhythm. 2003;18(1):80-90. https://doi. org/10.1177/0748730402239679.

18. Roenneberg T, Allebrandt KV, Merrow M, Vetter C. Social jetlag and obesity. Curr Biol. 2012;22(10):939-43. https://doi.org/10.1016/j.cub.2012.03.038.

19. Kim S, Dueker GL, Hasher L, Goldstein D. Children's time of day preference: age, gender and ethnic differences. Pers Individ Differ. 2002;33(7):1083-90. https://doi.org/10.1016/S0191-8869(01)00214-8.

20. Culnan E, Kloss JD, Grandner M. A prospective study of weight gain associated with chronotype among college freshmen. Chronobiol Int. 2013; 30(5):682-90. https://doi.org/10.3109/07420528.2013.782311.

21. Buboltz WC Jr, Soper B, Brown F, Jenkins S. Treatment approaches for sleep difficulties in college students. Couns Psychol Q. 2002;15(3):229-37. https:// doi.org/10.1080/09515070210151788.

22. Moo-Estrella J, Pérez-Benítez H, Solís-Rodríguez F, Arankowsky-Sandoval G. Evaluation of depressive symptoms and sleep alterations in college students. Arch Med Res. 2005;36(4):393-8. https://doi.org/10.1016/j.arcmed.2005.03.018.

23. Brown FC, Soper B, Buboltz WCJ. Prevalence of delayed sleep phase syndrome in university students. Coll Stud J. 2001;35(3):472-6.

24. Fleig D, Randler C. Association between chronotype and diet in adolescents based on food logs. Eat Behav. 2009;10(2):115-8. https://doi.org/10.1016/j. eatbeh.2009.03.002.

25. Maukonen M, Kanerva N, Partonen T, Kronholm E, Konttinen H, Wennman H, et al. The associations between chronotype, a healthy diet and obesity. Chronobiol Int. 2016;33(8):972-81. https://doi.org/10.1080/07420528.2016. 1183022. 
26. Prather AA, Leung C, Adler NE, Ritchie L, Laraia B, Epel ES. Short and sweet: associations between self-reported sleep duration and sugar-sweetened beverage consumption among adults in the United States. Sleep Health. 2016;2(4):272. https://doi.org/10.1016/j.sleh.2016.09.007.

27. Wilckens KA, Erickson Kl, Wheeler ME. Physical activity and cognition: a mediating role of efficient sleep. Behav Sleep Med. 2018;16(6):569-86. https://doi.org/10.1080/15402002.2016.1253013.

28. Malik VS, Popkin BM, Bray GA, Després JP, Hu FB. Sugar-sweetened beverages, obesity, type 2 diabetes and cardiovascular disease risk. Circulation. 2010;121(11):1356-64. https://doi.org/10.1161/CIRCULATIONAHA. 109.876185.

29. Hu FB, Malik VS. Sugar-sweetened beverages and risk of obesity and type 2 diabetes: epidemiologic evidence. Physiol Behav. 2010;99(1):47-54. https:// doi.org/10.1016/j.physbeh.2010.01.036.

30. Kleiman S, Ng SW, Popkin B. Drinking to our health: can beverage companies cut calories while maintaining profits. Obes Rev. 2012;13(3):25874.https://doi.org/10.1111/j.1467-789X.2011.00949.X.

31. Guo H, Zhao L, Xu X, Yu W, Ju L, Yu D. Consumption of sugar-sweetened beverages among 18 years old and over adults in 2010-2012 in China. Wei Sheng Yan Jiu. 2018;47(1):22 PMID:29903218.

32. Horne JA, Ostberg OA. Self-assessment questionnaire to determine morningness-eveningness in human circadian rhythms. Int J Chronobiol. 1976;4(2):97-110 PMID:1027738.

33. Chung KF, Cheung MM. Sleep-wake patterns and sleep disturbance among Hong Kong Chinese adolescents. Sleep. 2008;31(2):185-94. https:/doi.org/ 10.1093/sleep/31.2.185

34. Lovibond PF, Lovibond SH. The structure of negative emotional states: comparison of the depression anxiety stress scales (dass) with the beck depression and anxiety inventories. Behav Res Ther. 1995;33(3):335-43. https://doi.org/10.1016/0005-7967(94)00075-U.

35. Chan RCK, Xu T, Huang J, Wang Y, Zhao Q, Shum DHK, et al. Extending the utility of the depression anxiety stress scale by examining its psychometric properties in Chinese settings. Psychiatry Res. 2012;200(2-3):879-83. https:// doi.org/10.1016/j.psychres.2012.06.041.

36. Hayes AF. Introduction to mediation, moderation, and conditional process analysis: a regression-based approach. J Educ Meas. 2013;51(3):335-7. https://doi.org/10.5539/ass.v11n9p207.

37. Mackinnon DP, Lockwood CM, Williams J. Confidence limits for the indirect effect: distribution of the product and resampling methods. Multivariate Behav Res. 2004;39(1):99-128. https://doi.org/10.1207/s15327906mbr3901_4.

38. Rangan A, Zheng M, Olsen NJ, Rohde JF, Heitmann BL. Shorter sleep duration is associated with higher energy intake and an increase in BMI Zscore in young children predisposed to overweight. Int J Obes. 2017;42(1): 59-64. https://doi.org/10.1038/ijo.2017.216.

39. Sampasa-Kanyinga $H$, Hamilton HA, Chaput JP. Sleep duration and consumption of sugar-sweetened beverages and energy drinks among adolescents. Nutrition. 2018;48:77-81. https://doi.org/10.1016/j.nut.2017. 11.013.

40. Kanerva N, Kronholm E, Partonen T, Ovaskainen ML, Kaartinen NE, Konttinen $\mathrm{H}$, et al. Tendency toward eveningness is associated with unhealthy dietary habits. Chronobiol Int. 2013;29(7):920-7. https://doi.org/10.3109/07420528. 2012.699128.

41. Schubert E, Randler C. Association between chronotype and the constructs of the three-factor-eating-questionnaire. Appetite. 2008:51(3):501-5. https:// doi.org/10.1016/j.appet.2008.03.018.

42. Cappuccio FP, Taggart FM, Kandala NB, Currie A, Peile E, Stranges S, et al. Meta-analysis of short sleep duration and obesity in children and adults. Sleep. 2008;31(5):619-26. https://doi.org/10.1093/sleep/31.5.619.

43. Scheer FAJL, Hilton MF, Mantzoros CS, Shea SA. Adverse metabolic and cardiovascular consequences of circadian misalignment. Proc Natl Acad Sci U S A. 2009;106(11):4453-8. https://doi.org/10.1073/pnas.0808180106.

44. Ben Lazreg T, Zaouali M, Chaieb M, Dallel NL, Tabka Z, Zbidi A. Circadian leptin, insulin and cortisol rhythms in obese subjects. Biol Rhythm Res. 2007; 38(1):9-17. https://doi.org/10.1080/09291010600831380.

45. Lucassen EA, Zhao X, Rother Kl, Mattingly MS, Courville AB, Lilian DJ, et al. Evening chronotype is associated with changes in eating behavior, more sleep apnea, and increased stress hormones in short sleeping obese individuals. PLoS One. 2013;8(3):e56519. https://doi.org/10.1371/journal. pone.0056519.

46. Wolfson AR. Sleep schedules and daytime functioning in adolescents. Child Dev. 2010;69(4):875-87. https://doi.org/10.1111/j.1467-8624.1998.tb06149.x.
47. Fernándezreal JM, Ricart W. Insulin resistance and chronic cardiovascular inflammatory syndrome. Endocr Rev. 2003;24(3):278-301. https://doi.org/10. 1210/er.2002-0010

48. Pate RR, Pratt M, Blair SN, Haskell WL, Macera CA, Bouchard C, King AC. Physical activity and public health. A recommendation from the Centers for Disease Control and Prevention and the American College of Sports Medicine. JAMA. 1995;273(5):402-7. https://doi.org/10.1001/jama.273.5.402.

49. Summers JB, Kaminski JM. Nutrition, physical activity, and obesity. Lancet. 2002;360(9341):1249. https://doi.org/10.1016/S0140-6736(02)11249-9.

50. Vitale JA, Weydahl A. Chronotype, physical activity, and sport performance: a systematic review. Sports Med. 2017;47(9):1859-68. https://doi.org/10. 1007/s40279-017-0741-z

51. Rique GL, Fernandes Filho GM, Ferreira AD, de Sousa-Muñoz RL. Relationship between chronotype and quality of sleep in medical students at the federal university of Paraiba, Brazil. Sleep Sci. 2014;7(2):96-102. https://doi.org/10.1016/j.slsci.2014.09.004.

52. Romonava F, Tafoya SA, Gutiérrezsoriano J, Osorio Y, Carriedo P, Ocampo B, et al. The association between chronotype and perceived academic stress to depression in medical students. Chronobiol Int. 2016;33(10):1359-68. https://doi.org/10.1080/07420528.2016.1217230.

53. Matsushita M, Koyama A, Ushijima H, Mikami A, Katsumata Y, Kikuchi Y, et al Sleep duration and its association with sleepiness and depression in "roninsei" preparatory school students. Asian J Psychiatr. 2014;9:61-6. https://doi. org/10.1016/j.ajp.2014.01.006.

54. Wittmann M, Paulus M, Roenneberg T. Decreased psychological well-being in late 'chronotypes' is mediated by smoking and alcohol consumption. Subst Use Misuse. 2010;45(1-2):15-30. https://doi.org/10.3109/ 10826080903498952

\section{Ready to submit your research? Choose BMC and benefit from:}

- fast, convenient online submission

- thorough peer review by experienced researchers in your field

- rapid publication on acceptance

- support for research data, including large and complex data types

- gold Open Access which fosters wider collaboration and increased citations

- maximum visibility for your research: over $100 \mathrm{M}$ website views per year

At BMC, research is always in progress.

Learn more biomedcentral.com/submissions 